Publ. in: Applied Psychology: Health and Well-Being 2 (2010), 3, pp. 362-373

\title{
Better Liked but Not More Supported: Optimism and Social Support from a Provider's Perspective
}

\author{
Manja Vollmann* and Britta Renner \\ University of Konstanz, Germany
}

\begin{abstract}
Optimists commonly report a higher availability of supportive others and more received social support than pessimists. However, these results are silent on the question of whether this effect is due to an overly optimistic view on their social environment or whether the social environment actually provides optimists with more support than pessimists. Accordingly, the present study tested in an experimental design whether potential support providers react differently toward optimists, pessimists, and realists. Participants viewed videotaped interactions displaying either an optimistic, pessimistic, or realistic target person. Results show that the personality, the behavior, and the interpersonal attraction of optimists and realists were evaluated more positively than that of pessimists. Nonetheless, participants were equally or even less willing to provide social support to optimists compared to pessimists and realists. Thus, the greater amount of received support reported by optimists possibly represents an optimistically biased perception rather than a veridical reflection of the support they are provided with.
\end{abstract}

Keywords: optimism, pessimism, providers' perspective, social support

\section{INTRODUCTION}

When asking optimists, their social environment appears to be highly supportive towards them. In particular, optimists commonly report a higher availability of helpful others in case of need, a higher amount of received social support, and greater satisfaction with the support provided by the social network than pessimists (e.g. Brissette, Scheier, \& Carver, 2002; Karademas, 2006; Segerstrom, 2007). However, these results are not really surprising as optimists, by definition, are expected to view themselves and their environment in a more positive way than pessimists. Thus, optimists are most likely to report an optimistically biased amount of received social

* Address for correspondence: Manja Vollmann, University of Konstanz, Department of Psychology, P.O. Box 47, D-78457 Konstanz, Germany. Email: manja.vollmann@unikonstanz.de

Both authors declare that they have no conflicts of interest. 
support rather than an accurate reflection of it. From a theoretical and practical perspective, the question whether optimists are actually provided with more support than pessimists or whether they merely believe that they receive more support is fundamental, because the receipt of social support is assumed to be a vital mechanism mediating the beneficial effects of optimism on health (Peterson \& Bossio, 2001; Scheier \& Carver, 1987; Scheier, Carver, $\&$ Bridges, 2001). In line with this notion, empirical studies have shown that social support receipt mediates the relationship between optimism and health (e.g. Shen, McCreary, \& Myers, 2004; Trunzo \& Pinto, 2003). However, the question arises whether the positive health effects of optimism are caused by an actual greater amount of social support receipt or by positive illusions of social support receipt.

To examine whether optimists actually differ from pessimists in the amount of support they receive from their social environment, the perspective needs to be switched from the support recipient to the support provider (Dunkel-Schetter, Blasband, Feinstein, \& Herbert, 1992; Vollmann, Renner, \& Weber, 2007). However, virtually all studies on optimism and social support have focused on the recipients' perspective, while the providers' perspective has been widely neglected. Thus, the present study primarily aims at investigating whether potential support providers show a differential willingness to provide social support to optimists and pessimists dealing with stressful situations. Persons faced with a stressful situation are particularly likely to trigger support reactions within their social environment. Accordingly, stressful situations represent an appropriate context for examining social support processes (Dunkel-Schetter \& Skokan, 1990). In order to obtain a comprehensive understanding of the impact of optimism and pessimism on the social environment, a broad bandwidth of social responses was examined extending social support intentions. On the basis of previous research on interpersonal perception and the social impact of different coping behaviors, an array of social responses was selected, i.e. (a) evaluation of personality in terms of general achievement and social recognition, (b) perceived effectiveness and adequacy of the displayed behavior, and (c) interpersonal attraction (cf. Carver, Kus, \& Scheier, 1994; Montoya \& Horton, 2004; Helweg-Larsen, Sadeghian, \& Webb, 2002; Schwarzer \& Weiner, 1991; Silver, Wortman, \& Crofton, 1990; Vollmann et al., 2007). Furthermore, the controllability of the stressful situation, i.e. the extent to which the outcome of the situation can be influenced by one's own behavior, was systematically varied. This is based on previous findings suggesting that optimists' and pessimists' cognitive, emotional, and behavioral reactions towards stressful situations are moderated by the controllability of the situation. Optimists in comparison to pessimists are more likely to adapt their coping strategies to the controllability of the stressful situation and, thus, show a more effective coping behavior (Scheier, Weintraub, \& Carver, 1986; Solberg Nes \& Seger-

(C) 2010 The Authors. Applied Psychology: Health and Well-Being (C) 2010 International Association of Applied Psychology. 
strom, 2006). Moreover, it has been found that the controllability of the situation has a strong impact on social support intentions, with uncontrollable situations eliciting a higher willingness to provide social support (Schwarzer \& Weiner, 1991). Finally, the classical optimists-pessimists dichotomy was extended by including realists as a third personality type.

In summary, extending previous research, the goal of the present study was to examine social responses towards optimists, pessimists, and realists dealing with stressful situations differing in controllability. Social responses encompassed four response types: (a) willingness to provide social support, (b) personality evaluation, (c) evaluation of the displayed behavior, and (d) interpersonal attraction.

\section{METHOD}

\section{Participants}

Two hundred (non-psychology) students of the University of Konstanz, Germany ( $50 \%$ women, $M=23$ years, $S D=2.9)$ took part in the study.

\section{Design and Procedure}

In order to ascertain an ecologically valid but standardised investigation of social responses towards optimists, realists, and pessimists, an experimental approach in which the three personality types were presented via videotapes was realised. The experiment had a 3 "personality type" (optimist vs. realist vs. pessimist) $\times 2$ "situation" (controllable vs. uncontrollable situation) between-subjects design that was balanced for the sex of participants. The participants were randomly assigned to one of the six conditions.

Participants were invited to take part in a research project on interpersonal perception. They were asked to watch a videotaped conversation and to form an impression of the target person. Afterwards, they completed questionnaires assessing their social responses towards the target person (cf. Vollmann et al., 2007). Informed consent was appropriately obtained from all participants.

\section{Stimulus Materials}

The six presented videotapes displayed conversations between two flat-mates in a natural environment, i.e. a kitchen. All conversations were recorded with a male and a female flat-mate (target person). During the conversation, the target person tells her flat-mate that she has finished her studies and has applied for her dream job. In the controllable situation, she reports that her application was not accepted because the company also requested a one-day

(C) 2010 The Authors. Applied Psychology: Health and Well-Being (C) 2010 International Association of Applied Psychology. 
work sample before making the final decision. In the uncontrollable situation, her application was not accepted because the company had a hiring freeze. Results of a preliminary study showed that both situations were perceived as moderately stressful and as differing in their controllability (see also Weber, Vollmann, \& Renner, 2007, for a similar procedure). ${ }^{1}$ During the conversation, the target person enacted either an optimistic, pessimistic, or realistic behavior pattern in response to the stressful situation (see Appendix for excerpts of the conversations).

The behavior patterns enacted by the target person were adopted from previous studies using a multi-level procedure based on the act frequency approach to identify situation-specific thoughts, feelings, goals, and actions that laypersons perceived as prototypical of optimists, pessimists, and realists dealing with stressful situations (for details see Weber et al., 2007, and see Peterson, 2000). The prototypical behavior patterns have been validated on established measures of optimism and pessimism (Weber et al., 2007). The optimistic behavior patterns were negatively correlated with pessimistic explanatory style and positively correlated with dispositional optimism, selfefficacy, and hope. Conversely, the pessimistic behavior patterns were negatively associated with the optimism measures and positively associated with pessimistic explanatory style. The realistic behavior patterns were slightly positively related to hope and unrelated to dispositional optimism, generalised self-efficacy, and pessimistic explanatory style.

The enacted optimistic behavior patterns were characterised by a positive construal of the situation, positive outcome expectancies, positive feelings, and persistent goal pursuit of getting the dream job. In the uncontrollable situation, optimism was additionally represented by negative feelings and active efforts towards goal attainment. In both situations, the enacted pessimistic behavior pattern was characterised by a negative construal of the

${ }^{1}$ To verify the quality of the situations, 133 students ( $62 \%$ women, $M=22$ years, $S D=2.5$ ) were asked to rate the stressfulness and the controllability of each situation. Stressfulness was assessed by asking the participants how threatening this situation would be for them, with scores ranging from 1 (not at all threatening) to 7 (very threatening). Controllability was measured with two items: (a) "To what extent can you affect the further course of this situation by your own behavior?", with scores ranging from 1 (not at all) to 7 (completely); (b) "How likely is it that the situation will come to a good end through your own efforts?", with scores ranging from 1 (not at all likely) to 7 (very likely). Because the two items were highly correlated in both situations $(r=.69$ and $r=.70)$, the ratings were averaged, yielding a single score for controllability.

The results showed that both situations were rated as moderately stressful, even though the controllable situation $(M=3.15=1.48, S D=1.58)$ was judged as less threatening than the uncontrollable situation $(M=3.83, S D=1.58 ; t(132)=-4.64, p<.001)$. More importantly, the results also confirmed that the controllable situation $(M=5.38, S D=1.16)$ was perceived as significantly more controllable than the uncontrollable situation $(M=2.52, S D=1.36$; $t(132)=20.77, p<.001)$. Male and female participants did not differ significantly in their ratings, $t \mathrm{~s}(131)<2$, indicating that the target situations were not biased with regard to gender.

(C) 2010 The Authors. Applied Psychology: Health and Well-Being (C) 2010 International Association of Applied Psychology. 
situation, negative outcome expectancies, negative feelings, disengagement from the goal "dream job", withdrawal from the situation, and distress. The enacted realistic behavior patterns contained acceptance of the situation and affect control. Additionally, in the controllable situation, the realistic behavior pattern included positive feelings, persistent goal pursuit of getting the dream job, and active efforts towards goal attainment, whereas in the uncontrollable situation, the realistic behavior pattern was characterised by positive as well as negative feelings, disengagement from the goal "dream job", and re-engagement in other job alternatives.

\section{Measures}

The evaluation of the target's personality was assessed by six items adapted from Montoya and Horton (2004) with half of the items referring to general achievements (e.g. "The person will be successful in life") and half of the items referring to social recognition (e.g. "The person is well respected") $(\alpha=.87)$.

Participants evaluated the target's behavior (a) in respect to its adequacy by indicating how "adequate" and how "acceptable" $(r=.66)$ they perceived the displayed behavior, and (b) in respect to its effectiveness by rating how "effective" and how "successful" $(r=.83)$ the behavior was.

Interpersonal attraction was measured by seven items adapted from previous studies (e.g. Helweg-Larsen et al., 2002; Montoya \& Horton, 2004) assessing affective attraction (e.g. "How much do you like the person?") and behavioral attraction (e.g. "I would like to go to a campus party with the person") $(\alpha=.91)$.

The willingness to provide the target with social support was measured by five items adapted from Schwarzer and Weiner (1991), e.g. "I would be willing to spend time talking and listening" and "I would be willing to assist with small problems" ( $\alpha=.91)$.

For the manipulation check, participants rated how "optimistic", "pessimistic", and "realistic" the target person was.

All responses were given on a rating scale from 1 (not at all) to 7 (very much).

\section{RESULTS}

\section{Manipulation Check}

Participants clearly differentiated optimistic, pessimistic, and realistic targets in both situations. Optimistic targets were rated as more optimistic than both pessimistic and realistic targets; pessimistic targets were rated as more pessimistic than both optimistic and realistic targets, and realistic targets were 
rated as more realistic than both optimistic and pessimistic targets, $F_{\mathrm{s}}(2$, 197) $>34, p$ s $<.001, \eta^{2}>.26$, Bonferroni tests, $p$ s $<.001$.

\section{Analyses}

A 3 "personality type" (optimist vs. realist vs. pessimist) $\times 2$ "situation" (controllable vs. uncontrollable situation) ANOVA with post-hoc Bonferroni tests was performed for each dependent variable. The results of the analyses are summarised in Figure 1, which presents the mean ratings for the three personality types averaged across the two situations.

The personality of the target was rated significantly differently as a function of the factor "personality type", $F(2,194)=70.18, p<.001, \eta^{2}=.42$. Optimists and realists were evaluated as significantly more positive with regard to their general achievement and social recognition than pessimists in both situations, $p s<.05$. Additionally, the "personality type" $\times$ "situation" interaction attained significance, $F(2,194)=4.97, p<.01, \eta^{2}=.05$, indicating that in the controllable situation, the personality of the realist was evaluated more positively than that of the optimist ( $M=4.44, S D=1.04$ vs. $M=3.83$, $S D=1.15), p<.05$. No other effect was statistically significant, $F<1, n s$.

Regarding the adequacy of behavior, the main effect for the factor "situation" attained significance, $F(1,194)=7.04, p<.01, \eta^{2}=.04$. Independent of the personality type, participants evaluated the targets' behavior in the uncontrollable situation as more adequate than in the controllable situation $(M=4.18, S D=1.53$ vs. $M=3.74, S D=1.64)$. Importantly, the adequacy and the effectiveness of the target's behavior were also rated significantly differently for the three personality types, $F(2,194)=89.97, p<.001, \eta^{2}=.48$
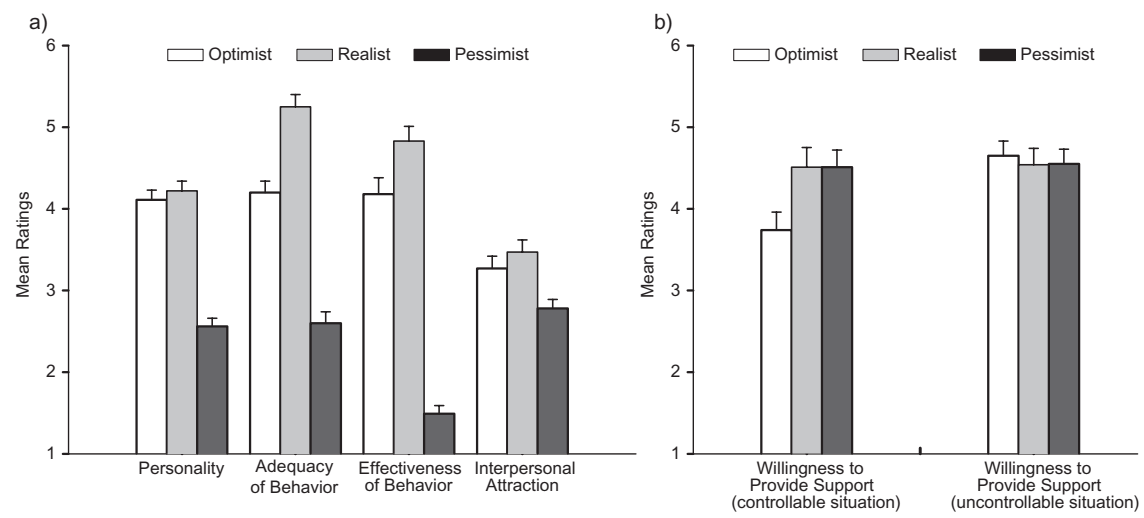

FIGURE 1. Mean ratings (with standard errors) for optimists, realists, and pessimists.

(C) 2010 The Authors. Applied Psychology: Health and Well-Being (C) 2010 International Association of Applied Psychology. 
and $F(2,194)=121.53, p<.001, \eta^{2}=.56$. In both situations, the behavior of optimists and realists was evaluated as being significantly more adequate and more effective than the behavior of pessimists, $p s<.001$. In addition, the behavior of realists was evaluated as being more adequate and more effective than the behavior of optimists, $p \mathrm{~s}<.05$. No other statistically significant effect emerged, $F \mathrm{~s}<3$, $n s$.

With regard to the reported interpersonal attraction, a significant main effect of "personality type" was obtained, $F(2,194)=6.72, p<.01, \eta^{2}=.07$. Participants were more attracted to optimists and realists than to pessimists, $p s<.05$. The same pattern of results emerged in both situations. No other effect reached statistical significance, $F \mathrm{~S}<2$, $n s$.

Importantly, the analysis of the reported willingness to provide the target with social support revealed no significant main effect for the factor "personality type", $F(2,194)=1.76$, ns. However, the "personality type" $\times$ "situation" interaction almost attained significance, $F(2,194)=4.30, p=.05$, $\eta^{2}=.03$. Additional analyses showed that in the uncontrollable situation, participants were equally willing to provide the optimist, realist, and pessimist with social support $(M=4.65, S D=1.06, M=4.54, S D=1.10$ and $M=4.55, S D=1.09)$. However, in the controllable situation, participants were less willing to provide social support to the optimist than to the realist and the pessimist $(M=3.74, S D=1.30$ vs. $M=4.51, S D=1.32$ and $M=4.51, S D=1.23), p s<.05$. No other effect was statistically significant, $F<4, n s$.

\section{DISCUSSION}

The present study investigated social responses towards optimists, realists, and pessimists from a provider's perspective. The pattern of social responses towards the three personality types was highly similar across the two situations differing in controllability and also across the provider's gender as confirmed by additional analyses. Moreover, the present results coincide with findings from previous studies using a different experimental paradigm (Vollmann et al., 2007), indicating reliability and generalisability of the findings.

In line with previous research, optimists were perceived as more favorable and likeable than pessimists (e.g. Carver et al., 1994; Helweg-Larsen et al., 2002). Although participants clearly had a more positive impression of optimists than of pessimists, they were, however, not more willing to provide optimists with social support than pessimists. Conversely, they were equally or even less willing to provide support to optimists compared with pessimists. Thus, optimists appear to be better liked but not more supported by their social environment. These findings suggest that the greater amount of received social support commonly reported by optimists represents a positive illusion rather than a veridical reflection of the support provided by the social 
environment. This in turn would imply that the relationship between optimism and health is not predominantly mediated by the actual receipt of social support, but rather by the perception of social support.

However, since the behavior of optimists compared to that of pessimists was evaluated as more adequate and more effective in dealing with both the controllable and the uncontrollable situations, one could argue that optimists are perceived as being less in need of social support than pessimists. Assuming that people are less willing to support those people who show a more effective coping behavior would lead to the prediction that realists should receive even less support than optimists. Contrary to this assumption, the data show that although the behavior of realists was rated as significantly more adequate and effective than that of optimists, they still elicited an equal or even a higher willingness to provide social support than optimists. Moreover, additional analyses also failed to provide evidence for the notion that support intentions might depend on the perceived effectiveness of the recipient's coping behavior since perceived effectiveness of the behavior was unrelated to the willingness to provide social support, $r=.11, n s$. Furthermore, it needs to be noted that intentions such as social support intentions are substantially but not perfectly related to subsequent behavior. In general, Abraham and Sheeran (2000) expect behavioral intention measures to account for 20-25 per cent of the variance in behavior measures.

Turning to the evaluation of personality and reported interpersonal attraction, the results suggest a huge advantage for optimists in comparison to pessimists. One might speculate that optimists predominantly base their perception of support on these positive attitudes of others towards them rather than the actual experience of social support receipt. Optimists might generalise the positive attitudes towards them in a "sense of acceptance" (e.g. Sarason, Pierce, \& Sarason, 1990) and therefore assume that they have more social support available in case of need. Thus, the positive relation between optimism and social support might be veridical in that positive attitudes held by our social environment towards us are the fuel for driving positive health outcomes rather than concrete social support behavior.

\section{ACKNOWLEDGEMENTS}

We wish to thank Aurelia Drocur, Helge Andreas Giese, and Franziska Unholzer for their great help with data collection.

\section{REFERENCES}

Abraham, C., \& Sheeran, P. (2000). Understanding and changing health behavior: From health beliefs to self-regulation. In P. Norman, C. Abraham, \& M. Conner (Eds.), Understanding and changing health behavior (pp. 3-24). Amsterdam: Harwood Academic Publishers.

(C) 2010 The Authors. Applied Psychology: Health and Well-Being (C) 2010 International Association of Applied Psychology. 
Brissette, I., Scheier, M.F., \& Carver, C.S. (2002). The role of optimism in social network development, coping, and psychological adjustment during a life transition. Journal of Personality and Social Psychology, 82, 102-111.

Carver, C.S., Kus, L.A., \& Scheier, M.F. (1994). Effects of good versus bad mood and optimistic versus pessimistic outlook on social acceptance versus rejection. Journal of Social and Clinical Psychology, 13, 138-151.

Dunkel-Schetter, C., Blasband, D.E., Feinstein, L.G., \& Herbert, T.B. (1992). Elements of supportive interactions: When are attempts to help effective? In S. Spacapan \& S. Oskamp (Eds.), Helping and being helped: Naturalistic studies (pp. 83-114). Thousand Oaks, CA: Sage Publications.

Dunkel-Schetter, C., \& Skokan, L.A. (1990). Determinants of social support provision in personal relationships. Journal of Social and Personal Relationships, 7, $437-450$.

Helweg-Larsen, M., Sadeghian, P., \& Webb, M.S. (2002). The stigma of being pessimistically biased. Journal of Social and Clinical Psychology, 21, 92-107.

Karademas, E.C. (2006). Self-efficacy, social support and well-being: The mediating role of optimism. Personality and Individual Differences, 40, 1281-1290.

Montoya, R., \& Horton, R.S. (2004). On the importance of cognitive evaluation as a determinant of interpersonal attraction. Journal of Personality and Social Psychology, 86, 696-712.

Peterson, C. (2000). The future of optimism. American Psychologist, 55, 44 55.

Peterson, C., \& Bossio, L.M. (2001). Optimism and physical well-being. In E.C. Chang (Ed.), Optimism and pessimism: Implications for theory, research, and practice (pp. 127-145). Washington, DC: American Psychological Association.

Sarason, B.R., Pierce, G.R., \& Sarason, I.G. (1990). Social support: The sense of acceptance and the role of relationships. In B.R. Sarason, I.G. Sarason, \& G.R. Pierce (Eds.), Social support: An interactional view (pp. 97-128). Oxford: John Wiley.

Scheier, M.F., \& Carver, C.S. (1987). Dispositional optimism and physical well-being: The influence of generalized outcome expectancies on health. Journal of Personality, 55, 169-210.

Scheier, M.F., Carver, C.S., \& Bridges, M.W. (2001). Optimism, pessimism, and psychological well-being. In E.C. Chang (Ed.), Optimism and pessimism: Implications for theory, research, and practice (pp. 189-216). Washington, DC: American Psychological Association.

Scheier, M.F., Weintraub, J.K., \& Carver, C.S. (1986). Coping with stress: Divergent strategies of optimists and pessimists. Journal of Consulting and Clinical Psychology, 51, 1257-1264.

Schwarzer, R., \& Weiner, B. (1991). Stigma controllability and coping as predictors of emotions and social support. Journal of Social and Personal Relationships, 8, $133-140$.

Segerstrom, S.C. (2007). Optimism and resources: Effects on each other and on health over 10 years. Journal of Research in Personality, 41, 772-786.

Shen, B.J., McCreary, C.P., \& Myers, H.F. (2004). Independent and mediated contributions of personality, coping, social support, and depressive symptoms to 
physical functioning outcome among patients in cardiac rehabilitation. Journal of Behavioral Medicine, 27, 39-62.

Silver, R.C., Wortman, C.B., \& Crofton, C. (1990). The role of coping in support provision: The self-presentational dilemma of victims of life crises. In B.R. Sarason, I.G. Sarason, \& G.R. Pierce (Eds.), Social support: An interactional view (pp. 397-426). Oxford: John Wiley.

Solberg Nes, L., \& Segerstrom, S.C. (2006). Dispositional optimism and coping: A meta-analytic review. Personality and Social Psychology Review, 10, 235-251.

Trunzo, J.J., \& Pinto, B.M. (2003). Social support as a mediator of optimism and distress in breast cancer survivors. Journal of Consulting and Clinical Psychology, $71,805-811$.

Vollmann, M., Renner, B., \& Weber, H. (2007). Optimism and social support: The providers' perspective. Journal of Positive Psychology, 2, 205-215.

Weber, H., Vollmann, M., \& Renner, B. (2007). The spirited, the observant, and the disheartened: Social concepts of optimism, realism, and pessimism. Journal of Personality, 75, 169-197. 


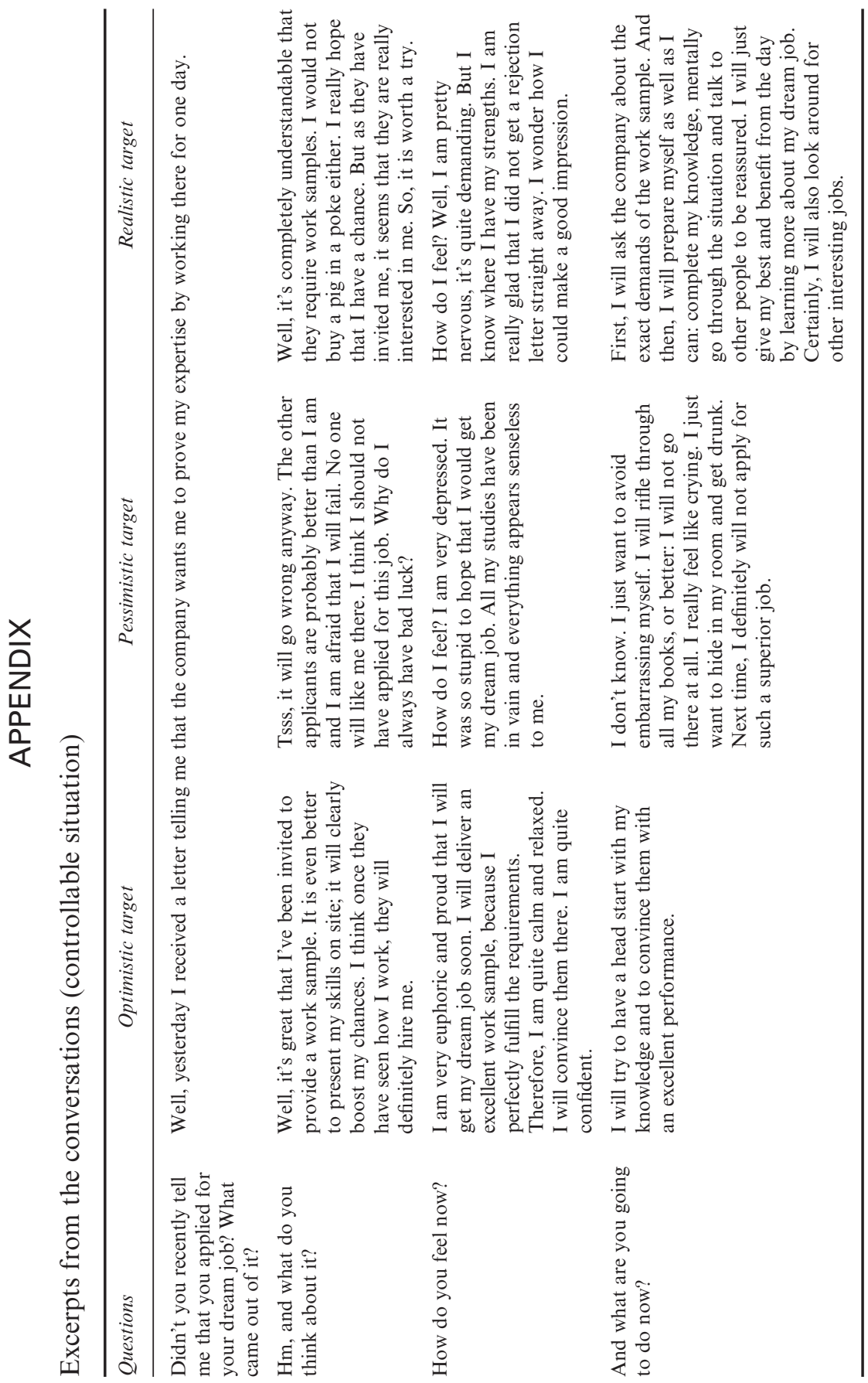

(C) 2010 The Authors. Applied Psychology: Health and Well-Being (C) 2010 International Association of Applied Psychology. 


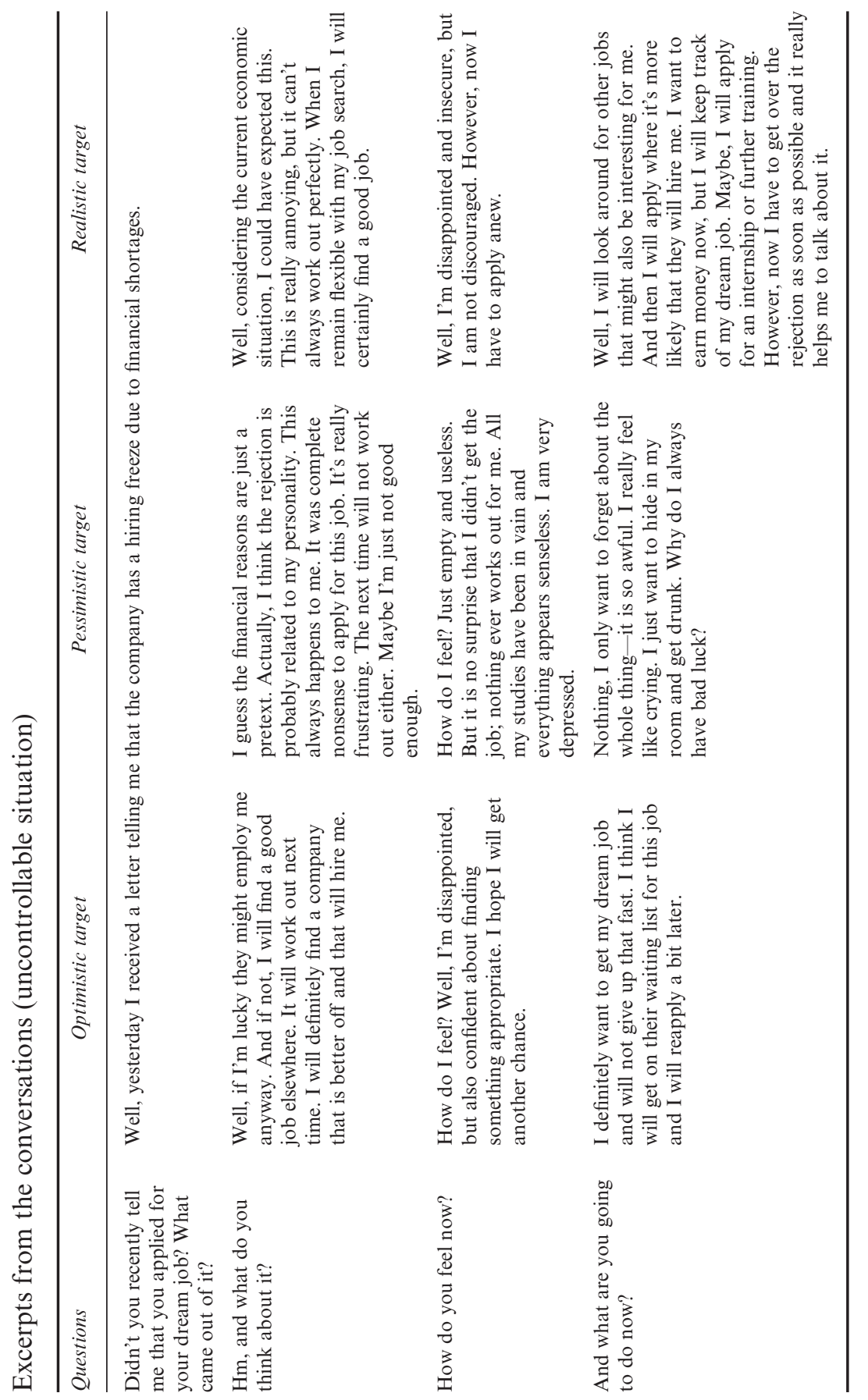

(C) 2010 The Authors. Applied Psychology: Health and Well-Being (C) 2010 International Association of Applied Psychology. 